\title{
Educação em saúde para mães com recém nascidos hospitalizados: relato de experiência
}

\author{
Health education for mothers with hospitalized newborns: experience report \\ Educación en salud para madres con recién nacidos hospitalizados: informe de experiencia
}

Recebido: 27/02/2021 | Revisado: 07/03/2021 | Aceito: 10/03/2021 | Publicado: 18/03/2021

\author{
Marcos Pires Campos \\ ORCID: https://orcid.org/0000-0002-9656-9140 \\ Universidade Estadual Vale do Acaraú, Brasil \\ E-mail: e14.marcos@gmail.com \\ Jessiane de Paulo Rodrigues \\ ORCID: https://orcid.org/0000-0001-5315-0262 \\ Universidade Estadual Vale do Acaraú, Brasil \\ E-mail: jessianeprodrigues99@gmail.com \\ João Victor Ferreira Sampaio \\ ORCID: https://orcid.org/0000-0003-4224-7442 \\ Universidade Estadual Vale do Acaraú, Brasil \\ E-mail: Joaovictorferreiras@ @otmail.com \\ Layse Fernandes Queiroz Vasconcelos \\ ORCID: https://orcid.org/0000-0002-0918-5545 \\ Universidade Estadual Vale do Acaraú, Brasil \\ E-mail: queirozflayse@gmail.com \\ Letícia de Souza Tomaz \\ ORCID: https://orcid.org/0000-0001-8875-5691 \\ Universidade Estadual Vale do Acaraú, Brasil \\ E-mail: leticiattomaz@gmail.com \\ Francisco Marcelo Leandro Cavalcante \\ ORCID: https://orcid.org/0000-0001-6143-1558 \\ Universidade Estadual Vale do Acaraú, Brasil \\ E-mail: marceloleandrocavalcante98@hotmail.com \\ Francisco Willian Melo de Sousa \\ ORCID: https://orcid.org/0000-0001-9852-6526 \\ Universidade Estadual Vale do Acaraú, Brasil \\ E-mail: williancarire123@gmail.com \\ Francisca Isaelly dos Santos Dias \\ ORCID: https://orcid.org/0000-0002-6420-4382 \\ Universidade Federal do Ceará, Brasil \\ E-mail: isaellydias@hotmail.com \\ Maria Adelane Monteiro da Silva \\ ORCID: https://orcid.org/0000-0001-7579-2645 \\ Universidade Estadual Vale do Acaraú, Brasil \\ E-mail: adelanemonteiro@hotmail.com \\ Cibelly Aliny Siqueira Lima Freitas \\ ORCID: https://orcid.org/0000-0002-0585-5345 \\ Universidade Estadual Vale do Acaraú, Brasil \\ E-mail: cibellyaliny @gmail.com
}

\begin{abstract}
Resumo
O estudo objetiva descrever as ações educativas realizadas com mães de crianças prematuras hospitalizadas. Trata-se de um relato de experiência, com abordagem qualitativa, desenvolvido por estudantes de Enfermagem, a partir de oficinas realizadas numa casa de apoio denominada Casa da Mamãe, vinculada a um hospital escola da região norte do Ceará. Os encontros foram realizados no período de maio a julho de 2019 e ocorriam semanalmente. Para coleta das informações utilizou-se o diário de campo, e posteriormente, fez-se análise dos registros junto à literatura. Realizou-se nove encontros com as puérperas, e nestes trabalhou-se, por meio de oficinas educativas e metodologias ativas as seguintes temáticas: cuidando do cuidador, cuidados com o recém-nascido, promovendo e compartilhando sentimentos, entre outras ações feitas por meio de dinâmicas, massagens, pinturas e arteterapia. As atividades realizadas com o grupo de puérperas proporcionaram momentos de aprendizagem a todos os envolvidos, reafirmando a ideia de que as ações de promoção à saúde devem ser eminentemente participativas e transformadoras. A equipe de acadêmicos de enfermagem auxiliou no favorecimento do vínculo, por meio das atividades de educação em saúde, momentos de relaxamento e de autoconhecimento, além de fortalecer a relação de apoio mútuo entre as mães.
\end{abstract}

Palavras-chave: Mães; Criança hospitalizada; Educação em saúde; Promoção da saúde; Enfermagem. 


\begin{abstract}
The study aims to describe the educational actions carried out with mothers of hospitalized premature children. It is an experience report, with a qualitative approach, developed by nursing students, from workshops held in a support house called Casa da Mamãe, linked to a teaching hospital in the north of Ceará. The meetings were held from May to July 2019 and took place weekly. To collect the information, the field diary was used, and later, the records were analyzed together with the literature. Nine meetings were held with the puerperal women, and the following themes were worked on through the following educational workshops and active methodologies: taking care of the caregiver, caring for the newborn, promoting and sharing feelings, among other actions done through dynamics, massages, paintings and art therapy. The activities carried out with the group of puerperal women provided learning moments for all those involved, reaffirming the idea that health promotion actions should be eminently participatory and transformative. The nursing academic team helped to favor the bond, through health education activities, moments of relaxation and self-knowledge, in addition to strengthening the relationship of mutual support between mothers.
\end{abstract}

Keywords: Mothers; Child, hospitalized; Health education; Health promotion; Nursing.

\title{
Resumen
}

El estudio tiene como objetivo describir las acciones educativas realizadas con madres de niños prematuros hospitalizados. Se trata de un relato de experiencia, con enfoque cualitativo, desarrollado por estudiantes de enfermería, a partir de talleres realizados en una casa de apoyo llamada Casa da Mamãe, vinculada a un hospital universitario en el norte de Ceará. Las reuniones se llevaron a cabo de mayo a julio de 2019 y se llevaron a cabo semanalmente. Para la recolección de la información se utilizó el diario de campo y posteriormente se analizaron los registros junto con la literatura. Se realizaron nueve encuentros con las puérperas, y en estos se trabajaron los siguientes temas a través de talleres educativos y metodologías activas: cuidar al cuidador, cuidar al recién nacido, promover y compartir sentimientos, entre otras acciones realizadas a través de dinámicas, masajes, pinturas y arteterapia. Las actividades realizadas con el grupo de puérperas brindaron momentos de aprendizaje para todos los involucrados, reafirmando la idea de que las acciones de promoción de la salud deben ser eminentemente participativas y transformadoras. El equipo académico de enfermería ayudó a favorecer el vínculo, a través de actividades de educación en salud, momentos de relajación y autoconocimiento, además de fortalecer la relación de apoyo mutuo entre las madres.

Palabras clave: Madres; Niño hospitalizado; Educación para la salud; Promoción de la salud; Enfermería.

\section{Introdução}

$\mathrm{O}$ aumento anual do número de recém nascidos prematuros constitui questão de saúde pública mundial, em que o parto prematuro representa a principal causa de morte de crianças menores de cinco anos. Estimativas da Organização Mundial da Saúde (OMS) sinalizam que, anualmente, nascem cerca de 15 milhões de recém-nascidos prematuros, sendo que o Brasil assume a décima colocação em relação ao número de partos prematuros, com ocorrência de mais de 279 mil casos (WHO, 2019).

Essa crescente tendência está relacionada, principalmente, às grandes taxas de cesarianas, às infecções geniturinárias, aos tratamentos para infertilidade, que aumentam o número de gestações gemelares, e, ainda, às intervenções médicas no processo de nascimento, como a indução medicamentosa precoce do trabalho de parto. Estima-se que em torno de 50\% dos casos de parto prematuro o fator etiológico não é bem definido, visto que resultaram da combinação de diversos fatores maternos e fetais (Demitto et al., 2017).

Nesse contexto, a ocorrência do nascimento prematuro gera repercussões psicológicas e emocionais na puérpera que vivencia o processo de hospitalização de seu filho por conta da prematuridade. Estudo realizado em Portugal identificou que as mães que tiveram parto prematuro enfrentaram sentimentos como medo pela vida da criança, angústias e desespero relacionadas ao parto precoce (Gonçalves et al., 2020). Pesquisa conduzida na Itália, com 62 mães de bebê prematuro, também identificou altos níveis de ansiedade e depressão nas participantes, em que foi observado que quanto mais prematura é a criança, maiores são os níveis desses transtornos nas mulheres, o que pode comprometer significativamente seu estado emocional, a autoimagem parental e a formação do vínculo precoce com o bebê (Trumello et al., 2018).

Destarte, a internação do filho configura-se como situação estressora para a mãe, haja vista que há comprometimento do contato entre o binômio mãe-filho, que desencadeia sentimentos de tristeza, fragilidade e insegurança no que diz respeito à 
vida do bebê. Soma-se a isso as dúvidas e preocupações relacionados à realização dos cuidados de seus filhos, que podem gerar ainda mais ansiedade e sentimentos de incapacidade (Barroso et al., 2015).

Tais dados evidenciam a necessidade de se desenvolver e implementar intervenções de apoio que busquem atender às necessidades da mãe, com o objetivo de mitigar os impactos psicológicos decorrentes do parto prematuro e fortalecer sua capacidade de enfrentamento e resiliência (MacKinnon et al., 2018). Um estudo de metanálise evidenciou que intervenções voltadas à promoção do suporte emocional diminuem significativamente o estresse em mães de bebês prematuros hospitalizados, assim como aumentam a confiança da mãe para desempenharam os cuidados com seu filho (VillamizarCarvajal et al., 2016).

Nesse sentido, as oficinas educativas como estratégias de promoção da saúde de forma holística e humanizada às puérperas são fundamentais para favorecer e fortalecer a construção de vínculos e minimizar o sofrimento biopsicossocial dessas mulheres, o que requer o olhar sensibilizado dos profissionais de saúde para implementação dessas ferramentas de cuidado, como também para favorecer o desenvolvimento de habilidades e competências do cuidador familiar frente ao processo de hospitalização e aos cuidados com seu filho (Araújo et al., 2020).

Ante o exposto, torna-se fundamental o desenvolvimento de novos estudos que abordem a implementação de intervenções educacionais para mães de bebês prematuros. Esse estudo mostra-se relevante ao passo que fomenta a prática da educação em saúde com o referido público, bem como fornece subsídios para planejamento e desenvolvimento de intervenções educativas para essas pacientes. Assim, o presente estudo objetivou descrever as ações educativas realizadas com mães de crianças prematuras hospitalizadas.

\section{Metodologia}

Trata-se de um estudo descritivo, do tipo relato de experiência, de abordagem qualitativa haja vista que envolve a investigação e interpretação subjetiva do pesquisador em relação ao fenômeno estudado (PEREIRA et al., 2018). A experiência foi desenvolvida por meio de oficinas educativas com mães de bebês prematuros hospitalizados e foi conduzida por acadêmicos de Enfermagem no período de maio a julho de 2019 em uma casa de apoio para esse público, intitulada Casa da Mamãe.

Essa vivência se deu por meio do Módulo Práticas Interdisciplinares em Ensino, Pesquisa e Extensão II (PIEPE II), que é componente da matriz curricular do curso de Enfermagem de uma universidade pública do interior do estado do Ceará. O módulo propõe aos estudantes a imersão em serviços de saúde para desenvolvimento de ações extensionistas voltadas à promoção da saúde materno-infantil, oportunizando a integração entre ensino, serviço e comunidade, bem como possibilitando aprimorar o processo de formação acadêmico-profissional e de transformação social pautada no tripé universitário.

A Casa da Mamãe se constitui um equipamento social de apoio vinculado a um hospital escola filantrópico localizado na região norte do estado do Ceará e abriga puérperas que residem na macrorregião do município de Sobral. Este equipamento social foi inaugurado no dia 20 de julho de 2001 e tem como proposta diminuir barreiras geográficas e socioeconômicas que dificultam o acesso das mães à instituição onde seus filhos ficam hospitalizados. Para ser admitida na casa, a mãe deve ter filho recém-nascido que necessite de cuidados especializados em decorrência da prematuridade, isto é, que necessitem de internação em Unidade de Terapia Intensiva (UTI) ou Unidade de Cuidados Intensivos (UCI).

Os encontros com as mães foram realizados semanalmente no período da tarde e tiveram duração média de uma hora. Foram realizadas oficinas de caráter lúdico, dinâmico e atrativo, pautadas na abordagem grupal. Utilizou-se o referencial teórico de Maxime Loomis, que orienta a condução do processo grupal conduzido por enfermeiros mediante operacionalização dos encontros em três fases: planejamento, intervenção e avaliação. $\mathrm{O}$ objetivo das atividades grupais, conforme proposto por Loomis, foi sanar as necessidades relatadas pelos participantes, prestar informação, promover o altruísmo, o desenvolvimento 
de técnicas de socialização, aprendizagem interpessoal, coesão grupal, catarse e fatores existenciais (Silva et al., 2011).

Assim, cada oficina foi dividida em três momentos diferentes: o primeiro, intitulado de 'quebra-gelo', foi destinado ao acolhimento e apresentação de cada participante, visto a alta rotatividade de mulheres na casa; o segundo momento constitui o desenvolvimento das intervenções educativas. E por fim, o terceiro momento representou a avaliação, em que as participantes tiveram a oportunidade de avaliar o momento realizado, com críticas, elogios e sugestões.

Para registro de informações referentes aos encontros educativos, utilizou-se o diário de campo, que configura-se como um instrumento pelo qual o estudante registra e analisa suas experiências, de modo a refletir e repensar as ações desenvolvidas em determinado cenário de atuação profissional (Silva et al., 2018). Posteriormente, fez-se a análise dos dados e sistematização das informações.

O presente estudo respeitou os aspectos éticos norteados pela Resolução No 466/2012 do Conselho Nacional de Saúde (CNS), garantido aos participantes autonomia, não maleficência, beneficência, justiça e equidade (BRASIL, 2012).

\section{Resultados}

A experiência foi descrita considerando-se a realização de um momento de imersão no serviço de saúde e, por conseguinte, cinco encontros educativos com um público de em média 11 mães. Devido a alta rotatividade dessas mulheres na Casa, em decorrência das novas admissões hospitalares e alta dos recém-nascidos, apenas duas participantes acompanharam as oficinas do primeiro ao último dia das ações. A partir da análise das informações, os achados foram apresentados em eixos temáticos para melhor compreensão das atividades realizadas.

\subsection{Imersão no âmbito hospitalar: traçando e construindo caminhos junto às puérperas}

Na primeira visita ao local, a enfermeira do Hospital e da Casa de Apoio realizou o acolhimento dos acadêmicos, momento no qual foi dialogado sobre a rotina das puérperas e os desafios que poderiam ser vivenciados na condução das atividades extensionistas no serviço, como a alta rotatividade, a introversão das mães e o horário disponível para a realização das ações, que poderia reduzir a participação do público-alvo. Apesar dessas situações, foi possível obter engajamento significativo das mães em cada oficina educativa.

Posteriormente, no mesmo encontro, foi realizada uma roda de conversa com as mães que se encontravam na casa, com o objetivo de identificar as necessidades das puérperas. Diante disso, identificou-se como prevalente a necessidade de manutenção do bem-estar físico e mental, bem como a necessidade de conhecimentos sobre os cuidados com seus filhos, na qual foram sugeridos pelas mulheres o desenvolvimento de oficinas com artesanato, sessões de relaxamento, orientações sobre o cuidado e alimentação do recém-nascido e momentos voltados para a saúde mental, já que elas enfrentavam inúmeros fatores estressantes ao longo do período na Casa da Mamãe.

Assim, com base nas necessidades e sugestões apresentadas pelas participantes, foram desenvolvidas cinco oficinas educativas, que estão descritas no Quadro 1 no que se refere à temática trabalhada, número de participantes, a metodologia empregada e materiais utilizados. 
Quadro 1. Descrição das oficinas desenvolvidas com mães com filhos prematuros hospitalizados. Sobral, CE, Brasil, 2021.

\begin{tabular}{|c|c|c|c|}
\hline Oficina & $\begin{array}{c}\mathbf{N}^{\circ} \text { de } \\
\text { participantes }\end{array}$ & Metodologia & Material \\
\hline Cuidando do cuidador & 10 & $\begin{array}{l}\text { - Quebra-gelo: socializar com o grupo uma } \\
\text { qualidade e um sentimento diante da situação } \\
\text { vivenciada. } \\
\text { - Desenvolvimento: momento de promoção do } \\
\text { relaxamento e bem-estar) } \\
\text { - Avaliação: socializar os pontos positivos, } \\
\text { negativos e sugestões. }\end{array}$ & $\begin{array}{l}\text { - Urso de pelúcia } \\
\text { - Hidratante }\end{array}$ \\
\hline $\begin{array}{l}\text { Cuidados com o recém- } \\
\text { nascido }\end{array}$ & 15 & $\begin{array}{l}\text { - Quebra-gelo: socializar uma palavra positiva } \\
\text { para as demais participantes. } \\
\text { - Desenvolvimento: dinâmica de mito e } \\
\text { verdade e compartilhamento de uma técnica } \\
\text { para acalmar os filhos; ensino da Técnica da } \\
\text { Shantala. } \\
\text { - Avaliação: socializar os pontos positivos, } \\
\text { negativos e sugestões. }\end{array}$ & $\begin{array}{c}\text { - Placa escrita mito e } \\
\text { verdade } \\
\text { - Hidratante } \\
\text { - Boneca }\end{array}$ \\
\hline $\begin{array}{l}\text { Promovendo e } \\
\text { compartilhando } \\
\text { sentimentos }\end{array}$ & 12 & $\begin{array}{l}\text { - Quebra-gelo: caixa das qualidades. } \\
\text { - Desenvolvimento: Em uma folha de papel } \\
\text { deveriam iniciar um desenho ao som de uma } \\
\text { música. } \\
\text { - Avaliação: socializar os pontos positivos, } \\
\text { negativos e sugestões. }\end{array}$ & $\begin{array}{l}\text { - Caixa de papelão } \\
\text { - Embrulhos de } \\
\text { presente } \\
\text { - Rosas artificiais } \\
\text { - Papel A4 } \\
\text { - Lápis de colorir }\end{array}$ \\
\hline $\begin{array}{c}\text { Arteterapia como } \\
\text { instrumento de promoção } \\
\text { à saúde }\end{array}$ & 09 & $\begin{array}{l}\text { - Quebra-gelo: momento de reflexão com a } \\
\text { pergunta: “o que é ser mãe?”. } \\
\text { - Desenvolvimento: Em uma folha de papel } \\
\text { teriam que desenhar ou escrever um desejo ou } \\
\text { uma saudade e ao final deveria compartilhar } \\
\text { com o grupo } \\
\text { - Avaliação: socializar os pontos positivos, } \\
\text { negativos e sugestões. }\end{array}$ & $\begin{array}{l}\text { - Papel A4 } \\
\text { - Canetas } \\
\text { esferográficas; } \\
\text { - Lápis de colorir }\end{array}$ \\
\hline $\begin{array}{l}\text { Construindo o mural da } \\
\text { esperança }\end{array}$ & 10 & $\begin{array}{l}\text { - Quebra-gelo: Deveriam falar duas verdades e } \\
\text { uma mentira, e o grupo adivinhar qual era a } \\
\text { falsa. } \\
\text { - Desenvolvimento: construção de um mural. } \\
\text { - Avaliação: socializar os pontos positivos, } \\
\text { negativos e sugestões. }\end{array}$ & $\begin{array}{l}\text { - Canetas } \\
\text { esferográficas } \\
\text { - Papel madeira } \\
\text { - Papel A4 } \\
\text { - Lápis de colorir }\end{array}$ \\
\hline
\end{tabular}

Fonte: Autores (2021).

Conforme descrito no Quadro 1, foram trabalhadas cinco temáticas, pautadas na abordagem grupal, que visaram a promoção da saúde mental das mães, bem como o empoderamento delas sobre os cuidados com seus filhos. Empregou-se materiais acessíveis como lápis de colorir, papel A4, urso de pelúcia, cujo objetivo foi oportunizar a participação ativa das mães, assim como facilitar a dinamicidade e interatividade ao longo das etapas de quebra-gelo, desenvolvimento e avaliação de cada oficina.

\subsection{Cuidando do cuidador}

No primeiro momento desta oficina foi realizada uma atividade de "quebra-gelo", como forma de cada sujeito apresentar-se ao grupo, que consistiu em falar uma qualidade ou um sentimento que iniciasse com a primeira letra do nome da participante. As principais expressões das participantes foram: força, esperança, fé e amor. Tais características evidenciaram sentimentos de esperança e motivação para o enfrentamento e superação do momento em que essas mães viviam.

No segundo momento, foi realizada atividade voltada à promoção do relaxamento e bem-estar, na qual foi orientado às participantes que fechassem os olhos e imaginassem uma paisagem ou lugar em que gostariam de estar naquele momento, 
enquanto que, simultaneamente, elas recebiam massagens nas mãos e nos ombros, realizadas pelos acadêmicos, além disso receberam um urso de pelúcia para proporcionar a estimulação sensorial do toque.

Com isso, foi possível promover o relaxamento e a redução do estresse relacionado às preocupações que envolvem o contexto de acompanhar o filho prematuro hospitalizado. Foi observado também que a forma como as mães seguravam o objeto simulava o contato com seus recém-nascidos e o desejo de estar com eles, na qual muitas delas se emocionaram com o momento. Uma das participantes relatou que nunca havia recebido uma demonstração de carinho e cuidado como esta.

Ao final, as participantes mostraram-se satisfeitas com a atividade, relatando que conseguiram relaxar e solicitaram que a temática fosse novamente realizada, apontando que o tempo de realização deveria ser estendido.

\subsection{Cuidados com o recém-nascido}

Nesta atividade, inicialmente sentadas em círculo, cada participante deveria apresentar ao grupo um sentimento positivo que desejava para as outras mulheres, em que foram mencionados os seguintes: cuidado, garra, fé, delicadeza, otimismo e perdão. Em seguida, foi realizada uma oficina educativa com uma dinâmica de perguntas e respostas sobre mitos e verdades a respeito dos cuidados com recém-nascidos prematuros. Nessa atividade dialogou-se sobre: amamentação, vacinação, alimentação, cuidados de higiene, dentre outros assuntos.

Além do mais, ensinou-se às mães a técnica Shantala, por meio de simulação em um manequim, em que foram abordados os cuidados e formas de realização. Essa técnica terapêutica tem sido amplamente utilizada devido seus inúmeros benefícios como fortalecimento do vínculo mãe e filho, bem como proporcionar relaxamento, bem-estar, alívio da dor, melhora da qualidade do sono do bebê e manutenção dos parâmetros vitais da criança (Carneiro et al., 2020; F. L. da Silva et al., 2020).

Conforme relatos dos participantes, o momento mostrou-se oportuno por propiciar conhecimentos às mães para desempenharem os cuidados com seus filhos, assim como oportunizou a retirada de dúvidas e esclarecimento de informações falsas.

\subsection{Arteterapia: promovendo e compartilhando bons sentimentos}

Nesta atividade, inicialmente foi entregue um objeto em formato de presente, com vários embrulhos, no qual em cada embrulho estava escrita uma qualidade. Cada participante, em sua vez, retirou um embrulho e escolheu uma das mulheres que possuía aquela característica para receber o presente. No último embrulho, o atributo descrito era "gentil", em que a participante apontada pelas outras como a mais gentil, ao abri-lo, recebeu a orientação de praticar a gentileza atribuída e dividilo com todo o grupo. Assim, cada participante recebeu uma rosa artificial, que era o presente da caixa, de forma a estimular o autoconhecimento e o apoio mútuo.

Como intervenção, pediu-se que cada participante iniciasse um desenho que representasse algo importante, um sentimento positivo, em uma folha de papel A4. Enquanto isso, uma música seria tocada e quando parada, elas deveriam repassar a folha em sentido horário para outra participante continuar a elaboração do desenho, até este passasse por todos os membros no grupo e voltar a pessoa que o iniciou. Ao final, foram questionadas se receberam os papéis como haviam planejado, e todas responderam que não, pois não tinham tempo hábil para esclarecer o que fora desenhado e a continuação deste desenho por outra pessoa era comprometida. Diante disso, buscou-se explicar que todas tinham sua subjetividade e particularidades, mas que juntas poderiam complementar uma a outra com sentimentos positivos e apoio mútuo.

Uma das mães também escreveu uma carta para sua filha com Síndrome de Down, cuja leitura gerou grande emoção no grupo. Frente a isso, todas as participantes avaliaram a oficina como emocionante. 


\subsection{Arteterapia: instrumento de promoção à saúde}

Para iniciar o encontro, as mães foram reunidas em círculo e questionadas sobre o que é ser mãe. Elas descreveram ser alguém que possui força, fé, paciência, amor, responsabilidade, dentre outras características. Diante disso, a intervenção consistiu na elaboração de um desenho ou escrita que expressasse o desejo ou algo que lhes trouxesse saudade, em um papel A4, para compartilhar com o grupo. No momento de socialização, as palavras e desenhos demonstraram a vontade das participantes de voltarem para suas casas com seus filhos. Estas avaliaram o momento como muito especial, ressaltando a importância da roda de conversa, uma vez que proporcionou um momento de desabafo e ajuda mútua, com o compartilhamento de sentimentos.

\subsection{Construindo o mural da esperança}

$\mathrm{Na}$ atividade de acolhida, cada participante relatou dois fatos/características e uma mentira a seu respeito. Em sequência, cada integrante do encontro buscou adivinhar qual a característica falsa e a verdadeira, favorecendo o conhecimento e a formação de vínculo entre os sujeitos.

A metodologia utilizada para a atividade de intervenção foi a criação de um mural que ficou exposto na casa. A ideia da construção desse mural partiu das próprias mães, que desejaram deixar no local os trabalhos realizados nas outras atividades para que as próximas moradoras pudessem vê-los. O mural foi confeccionado em folha de papel madeira e decorado com a ajuda de todas as participantes e acadêmicos, com uma moldura de desenhos, colagens, mensagens de apoio, bem como textos sobre suas próprias histórias para que as próximas mães que viesse a necessitar da casa de apoio pudessem visualizar e encontrar motivação.

Por fim, as participantes relataram que a atividade foi prazerosa e motivadora, mostrando-se fundamental para o auto fortalecimento e prestação de apoio a outras mães.

\section{Discussão}

As atividades desenvolvidas foram construídas mediante diagnóstico situacional das principais necessidades das mães, isto é, a promoção do bem-estar mental e aquisição de conhecimentos sobre os cuidados com seus filhos. Diante disso, as temáticas trabalhadas pautaram-se na mitigação das situações estressoras decorrentes do cotidiano do grupo, em que empregaram-se metodologias ativas para fortalecer as relações interpessoais e favorecer a manutenção do autocuidado e do bem-estar biopsicossocial das mães.

Nesse contexto, as vivências práticas fundamentadas no trabalho em equipe e na abordagem grupal foram fatores primordiais para o alcance dos objetivos propostos, de forma a promoveram estímulo à ajuda mútua, ao bem-estar emocional e resiliência, o que mostrou-se como terapêutica importante para as mães.

Frente a isso, sabe-se que a hospitalização do RN constitui-se desafiadora para as mães e familiares, principalmente quando se considera a idealização e desejo do nascimento do bebê de forma saudável e sem complicações. Durante a vivência, as mães mostraram-se muito sensíveis, em todos os encontros elas se emocionaram. Foi perceptível a tensão delas quando o telefone da casa tocava devido ao receio de receber notícias difíceis. Muitas das vezes, algumas eram convocadas à UTIN devido a uma piora do quadro clínico de seu filho ou para receber algumas informações dos profissionais.

Uma pesquisa realizada em uma Unidade de Tratamento Intensivo Neonatal-UTIN de um hospital público e privado, na região sul do Brasil, mostrou que todos os pais idealizavam ir para casa após o nascimento, e quando eles receberam a notícia de que seus filhos teriam que ficar internados, surgiram sentimentos de aflição e desespero, além do medo de não poder ficar do lado deles durante todo o dia. Alguns sentiam-se culpados, com a percepção de que tiveram atitudes inadequadas ao longo da gravidez que resultaram na prematuridade ou na internação da criança (Baseggio et al., 2017). 
Conforme foi observado no cotidiano das participantes, denota-se que cuidar da saúde mental dessas mães é de suma importância, haja vista que muitas delas enfrentam meses com a hospitalização prolongada do filho, vivenciando momentos de medo e estresse com os fatores relacionados à saúde de seu filho. Apesar disso, também encontram sentimentos de esperança com a possibilidade de alta hospitalar e desejo de melhora do estado de saúde dos filhos, aspectos esses que precisam ser potencializados mediante apoio da equipe multiprofissional de saúde (Carvalho \& Pereira, 2017).

Entretanto, estudos realizado em hospital universitário de Mato Grosso do Sul com 52 mães com filhos hospitalizados, identificou, de acordo com os discursos das participantes, a falta de atividades que contribuíssem com amenização da monotonia da rotina no hospital, o que revela a necessidade de ampliar essas ações nas unidade de internação neonatal e pediátrica (Zanfolim et al., 2018).

Assim, as ações educativas voltadas à promoção da esperança e de suporte emocional adquirem-se fundamental importância para às mães, visto que a esperança é potencial mecanismo de enfrentamento, que proporciona conforto e facilita a capacidade de resiliência e a perseverança das mães à atual situação (Cabeça \& Melo, 2020).

Nessa perspectiva, na experiência aqui descrita, foram desenvolvidas oficinas de educação e promoção à saúde, com o intuito de melhorar o bem-estar das mães frente ao processo de internação de seus filhos. Na atividade sobre os cuidados com o $\mathrm{RN}$, foi socializada com o grupo uma técnica indiana milenar para acalmar crianças, chamada de shantala, na qual consiste em uma massagem com óleo mineral ou hidratante. A técnica apresentada é bastante positiva para o RN, já que é um meio não farmacológico utilizado para o alívio da dor. (Silva et al., 2020). Foi possível notar o entusiasmo das mães a oficina e conhecimento repassadas, evidenciando que a importância das atividades educativas para empoderamento e construção de aprendizados dessas mulheres.

A oficina sobre a arteterapia, proporcionou às puérperas momento de leveza, criatividade e de demonstrações de sentimentos e expressões. Essa técnica cognitivo-comportamental, não farmacológica, é utilizada para tratamento e redução de danos psicológico em pacientes com quadros de sofrimento mental, estimulando a reflexão pela arte e concentração do momento vivenciado, sendo uma forma de desabafo para esses pacientes (Abbing et al., 2018).

Um fato que chamou a atenção da equipe de estudantes durante a realização de uma atividade, esteve relacionado com as flores que elas receberam, da pessoa mais gentil do grupo, quando elas receberam a flor muitas disseram que iriam levar para os profissionais de saúde que estavam cuidando de seus filhos. Esse gesto de empatia também foi evidenciado em estudo realizado com mães que tinham filhos hospitalizados em UTIN. Elas demostraram gratidão aos profissionais devido aos cuidados prestados a seus filhos (Zanfolim et al., 2018).

Diante disso, ressalta-se que o cuidado em saúde precisa perpassar o acolhimento da mãe e da família, com o fortalecimento do vínculo de confiança para com a equipe de saúde, o que se mostra relevante para humanizar a assistência à saúde prestada e possibilitar a abordagem para além do processo saúde-doença, que se considere os aspectos biopsicossociais e determinantes de saúde que influenciam no bem-estar das mães (Veronez et al., 2017).

Foi identificada como uma das principais demandas das mães um momento para cuidar da autoestima, isto é, um dia da beleza, haja vista que sofreram redução de ações de autocuidado devido às baixas condições financeiras ou ao fato da dedicação exclusiva aos cuidados dos filhos. Com a hospitalização dos filhos, ocorre a ruptura com a rotina de cuidados pessoais, o que suscita nas mães a necessidade e importância de manter os cuidados com sua aparência (Silva et al., 2018). Em decorrência do tempo reduzido disponibilizado para o desenvolvimento das ações educativas, não foi possível proporcionar esse momento às participantes.

Assim, conforme relatado pelas mães, as oficinas desenvolvidas foram fundamentais para oportunizar a mitigação desses fatores estressantes e melhorar seu bem estar biopsicossocial, demonstrando a necessidade de sensibilização dos profissionais que atuam com esse público para o desenvolvimento e implementação de intervenções que busquem facilitar o 
processo de enfrentamento das mães à hospitalização de seus filhos.

\section{Considerações Finais}

As atividades grupais realizadas no grupo de puérperas da Casa da Mamãe proporcionaram momentos de ampla aprendizagem a todos os envolvidos, reafirmando a ideia de que as ações de promoção à saúde devem ser eminentemente participativas e transformadoras. Além disso, foi possível observar que algumas mães do grupo apresentavam um conhecimento incipiente acerca das temáticas abordadas, e com a realização de abordagem grupal foi possível suprir a carência de ações coletivas de caráter educativo, que visam o aprendizado de diversas formas, além da socialização de informações.

A equipe de acadêmicos de enfermagem pôde auxiliar no favorecimento do vínculo, por meio das atividades de educação em saúde, momentos de relaxamento e de autoconhecimento, além de fortalecer o apoio mútuo entre as mães, refletindo de maneira significativa no cuidado integral ao RN e à sua família. Ressalta-se, portanto, a importância da promoção das ações de educação em saúde grupais de maneira lúdica e com a utilização de metodologias ativas, haja vista que tais dinâmicas proporcionaram a participação e o compartilhamento de informações entre as puérperas, o que se torna relevante por possibilitar a expressão de seus sentimentos, dúvidas e anseios, além de momentos de relaxamento.

Destaca-se que a presente experiência apresentou algumas limitações como o horário estabelecido para os encontros, momento esse destinado para o descanso, dificultando a participação das mães. Outro contratempo era o tempo reduzido para realização das atividades.

Por fim, sugere-se o desenvolvimento de novos estudos que busquem identificar as repercussões do nascimento prématuro para os pais, bem como estudos experimentais intervencionistas que busquem implementar e avaliar a efetividade de ações de educação em saúde para as mães de bebês prematuros.

\section{Referências}

Abbing, A., Ponstein, A., van Hooren, S., de Sonneville, L., Swaab, H., \& Baars, E. (2018). The effectiveness of art therapy for anxiety in adults: A systematic review of randomised and non-randomised controlled trials. PLoS ONE, 13(12), 1-19. https://doi.org/10.1371/journal.pone.0208716

Araújo, M. A. de P., Siqueira Lima Freitas, C. A., Alves Monteiro da Silva, M. A., Sampaio Melo, E., \& Martins da Silva, G. F. (2020). O cuidado de crianças com necessidades especiais em foco: o olhar de enfermeiros em unidades de terapia intensiva. Revista Enfermagem Atual In Derme, 93(31), 1-8. https://doi.org/10.31011/reaid-2020-v.93-n.31-art.764

Barroso, M. L., Pontes, A. L. de, \& Rolim, K. M. C. (2015). Consequences of prematurity in the establishment of the affective bond between teenage mothers and newborns. Revista Da Rede de Enfermagem Do Nordeste, 16(2), 168-175. https://doi.org/10.15253/2175-6783.2015000200005

Baseggio, D. B., Schneider Dias, M. P., Brusque, S. R., Donelli, T. M. S., \& Mendes, P. (2017). Vivências de mães e bebês prematuros durante a internação neonatal. Temas Em Psicologia, 25(1), 153-167. https://doi.org/10.9788/TP2017.1-10

BRASIL. (2012). Resolução No 466, De 12 De Dezembro De 2012. 66, 37-39. https://conselho.saude.gov.br/resolucoes/2012/Reso466.pdf

Cabeça, L. P. F., \& Melo, L. de L. (2020). From despair to hope: copying of relatives of hospitalized children before bad news report. Revista Brasileira de Enfermagem, 73(Suppl 5), e20200340. https://doi.org/10.1590/0034-7167-2020-0340

Carneiro, D. R. da C., Santos, E. S. dos, Oliveira, G. da P. L., Neves, L. N. A., \& Araújo, M. R. de S. (2020). Shantala in the primary health care for the promotion of children care: experience report. Rev Enferm UFPI, 9, 1-4. https://doi.org/10.26694/reufpi.v9i0.8794

Carvalho, L. da S., \& Pereira, C. de M. C. (2017). As reações psicológicas dos pais frente à hospitalização do bebê prematuro na UTI neonatal Psychological reactions of parents for hospitalization of premature infants in the neonatal ICU. Revista Sbph, 20(2), 101-122.

Demitto, M. de O., Gravena, A. A. F., Dell'Agnolo, C. M., Antunes, M. B., \& Pelloso, S. M. (2017). High risk pregnancies and factors associated with neonatal death. Revista Da Escola de Enfermagem Da USP, 51(0), 1-7. https://doi.org/10.1590/s1980-220x2016127103208

Gonçalves, J. L., Fuertes, M., Alves, M. J., Antunes, S., Almeida, A. R., Casimiro, R., \& Santos, M. (2020). Maternal pre and perinatal experiences with their full-term, preterm and very preterm newborns. BMC Pregnancy and Childbirth, 20(1), 1-16. https://doi.org/10.1186/s12884-020-02934-8

MacKinnon, A. L., Houazene, S., Robins, S., Feeley, N., \& Zelkowitz, P. (2018). Maternal attachment style, interpersonal trauma history, and childbirthrelated post-traumatic stress. Frontiers in Psychology, 9(NOV), 1-11. https://doi.org/10.3389/fpsyg.2018.02379 
Research, Society and Development, v. 10, n. 3, e35010313380, 2021

(CC BY 4.0) | ISSN 2525-3409 | DOI: http://dx.doi.org/10.33448/rsd-v10i3.13380

Pereira, A. S., Shitsuka, D. M., Pereira, F. J., Shitsuk, R. (2018). Metodologia da pesquisa científica. UFSM. https://repositorio.ufsm.br/bitstream/handle/1/15824/Lic_Computacao_Metodologia-Pesquisa-Cientifica.pdf?sequence=1

Silva, C. C. da, Silva, E. D. da, \& Rocha, L. L. B. (2018). O Salão De Beleza Como Recurso No Acompanhamento Das Mães De Recém-Nascidos Internados Na Unidade De Terapia Intensiva Neonatal. Cadernos Brasileiros de Terapia Ocupacional, 26(3), 569-579. https://doi.org/10.4322/2526-8910.ctoao1122

Silva, F. L. da,Cantalice, A. da S. C., Negreiros, R. V. de, Carvalho, M. A. P. de, Nascimento, J. A. D. de L., \& Abreu, R. A. de. (2020). Shantala as nonpharmacological therapy for pain relief in hospitalized children. Research, Society and Development, 9(10), 1-15. https://doi.org/10.33448/rsd-v9i10.8610

Silva, M. A. M. da, Souza, Â. M. A. e, \& Pinheiro, A. K. B. (2011). Coordenação de Grupos: Processo Grupal para Enfermeiros. (Expressão).

Trumello, C., Candelori, C., Cofini, M., Cimino, S., Cerniglia, L., Paciello, M., \& Babore, A. (2018). Mothers' depression, anxiety, and mental representations after preterm birth: A study during the infant's hospitalization in a neonatal intensive care unit. Frontiers in Public Health, 6(DEC), 1-9. https://doi.org/10.3389/fpubh.2018.00359

Veronez, M., Borghesan, N. A. B., Corrêa, D. A. M., \& Higarashi, I. H. (2017). Vivência de mães de bebês prematuros do nascimento a alta: notas de diários de campo. Revista Gaúcha de Enfermagem, 38(2), e60911. https://doi.org/10.1590/1983-1447.2017.02.60911

Villamizar-Carvajal, B., Vargas-Porras, C., \& Gómez-Ortega, O. R. (2016). Meta-analysis: Effect of interventions to reduce the stress level of parents of premature babies. Aquichan, 16(3), 276-295. https://doi.org/10.5294/aqui.2016.16.3.2

WHO. (2019). Survive and thrive: transforming care for every small and sick newborn. In World Health Organization, 29(8). https://apps.who.int/iris/bitstream/handle/10665/326495/9789241515887-eng.pdf

Zanfolim, L. C., Cerchiari, E. A. N., \& Ganassin, F. M. H. (2018). Dificuldades Vivenciadas pelas Mães na Hospitalização de seus Bebês em Unidades Neonatais. Psicologia: Ciência e Profissão, 38(1), 22-35. https://doi.org/doi.org/10.1590/1982-3703000292017 